\title{
The effects of placental insufficiency on the fetal lung
}

\author{
J. S. WIGGLESWORTH
}

From the Department of Paediatrics and Neonatal Medicine, Hammersmith Hospital, London

Any discussion of this subject 10 to 15 years ago would of necessity have been limited to morbid anatomical concepts with descriptions mainly of inhaled amniotic debris and the possible prenatal origin of hyaline membrane disease (HMD). With the advances in knowledge of fetal pulmonary physiology, the production and absorption of lung liquid, surfactant synthetic pathways and fetal breathing movements, we are now in a position to consider the possible effects of placental insufficiency in terms of altered fetal pulmonary physiology.

In this paper I propose to consider how placental insufficiency may impinge on the functional activities of the developing lung and how this may affect adaptation to extrauterine respiration. $I$ intend to be thoroughly provocative and to use available evidence to construct a tenuous hypothesis of my own on the mechanisms responsible for normal control of fetal lung growth and the triggering of biochemical lung maturation.

\section{Normal Lung Development}

The early phase of normal development up to 16 weeks' gestation consists of progressive increase in bronchial branching pattern. Beyond this stage normal growth involves gradual elaboration of the terminal airways (respiratory bronchioles, transitional ducts) and air sacs (Hislop and Reid, 1974). Blood-air barriers are first seen at 17 weeks' gestation (Boyden, 1974), and increase progressively thereafter. True alveoli develop after birth. Osmiophilic granules within the alveolar lining cells are seen from about 22 weeks, and the lung may have stable characteristics on static pressure volume loop measurements from 24 weeks' gestation (Reynolds et al, 1968). Maturation of the surfactant synthetic pathways with the appearance of excess lecithin within the amniotic fluid occurs by about 35 weeks (Gluck and Kulovich, 1973). Lung maturation is under the control of the pituitary-adrenal axis. Induction of enzymes concerned in surfactant synthesis is probably achieved by the action of endogenous cortisol on receptors in the fetal lung cells (Blackburn et al, 1973).

Fetal respiratory movements are seen in man from about 12 weeks' gestation as low-amplitude movements of the chest wall at a rate of 30 to 70 per minute (Boddy and Dawes, 1975). They are irregular at first but become more regular from 20 weeks' gestation onwards. The movements come in bursts and are present in from 55 to 90 per cent of the time. They occur during periods of rapid eye movement sleep (Dawes et al, 1972) and have been shown, in the lamb, to be under central nervous control (Condorelli and Scarpelli, 1975). Only small movements of tracheal fluid are produced by this respiratory activity.

Most information on the alveolar liquid comes from studies on the lamb. In the mature lamb fetus the liquid, an ultrafiltrate of plasma, with a relatively low protein content, is secreted at a rate of $0.036 \mathrm{ml}$ per $\mathrm{kg}$ weight per minute (Normand et al, 1971). The fluid does not appear to be reabsorbed by the lung in fetal life so that there is a net outflow into the amniotic fluid. The normal fetal lung is thus a highly active organ despite its lack of utilization as an organ of gas exchange.

\section{Effects of Acute Placental Insufficiency}

It is possible to postulate a sequence of events in acute hypoxia although many details inevitably remain obscure. The studies of Dawes and coworkers (Boddy and Dawes, 1975) have shown that hypoxia rapidly causes normal fetal breathing to cease. If hypoxia is prolonged the apnoeic phase is followed by a period of inspiratory gasps. Unlike normal fetal breathing the gasping of hypoxia causes considerable fluid movement and results in the aspiration of amniotic fluid, epithelial squames and meconium deep into the lung acini down to the level of the respiratory bronchioles and transitional ducts.

There is evidence that some factor associated with asphyxia predisposes to the later development of HMD both from work on lambs (Reynolds et al, 
1965) and in humans (Rudolph et al, 1966). Since a low $\mathrm{pH}$ is known to inhibit surfactant synthesis by the methylation pathway (Gluck et al, 1967), this might be regarded as an adequate explanation. The problem is rather more complicated than this as caesarean section performed before the onset of labour is more frequently associated with subsequent HMD than caesarean section performed during labour (Fedrick and Butler, 1972), although one would expect the latter to be the more asphyxial situation. It has been suggested that cortisol secretion associated with the onset of labour may aid lung maturation in the latter group (Fedrick and Butler, 1972).

In the days when HMD was believed to be due to amniotic inhalation the answer seemed quite simple as an intact amniotic sac would allow fluid to be inhaled more readily (Snyder, 1961). Personally, I think it would be most useful to know what happens to alveolar liquid formation and movement in severe hypoxia. It seems possible that a change in alveolar wall permeability might occur, which would allow reabsorption of lung liquid and its contained surfactant into the fetal circulation.

\section{Effects of Chronic Placental Insufficiency}

As an example of chronic placental insufficiency we can consider the effects of maternal preeclampsia. With prolonged preeclampsia there is generalized fetal growth retardation, but growth of different organs may not all be impaired to the same extent. Lung growth appears to be rather more impaired than that of organs such as the brain (Brans and Cassady, 1975). Observations of fetal breathing by ultrasonic techniques show that fetal respiration is decreased or absent in such growth-retarded infants (Boddy and Dawes, 1975). If acute hypoxia supervenes gasping movements will occur as a terminal event. Measurements of the lecithin:sphingomyelin ratios in samples of amniotic fluid in cases of preeclampsia and other forms of chronic maternal hypertension indicate, however, relative maturity of the surfactant-producing pathways (Gluck and Kulovich, 1973).

The situation may be summarized as one leading to decreased growth and increased maturity of the lungs with increased risk of amniotic inhalation.

\section{Conditions Associated with Loss or Failure of Formation of Amniotic Fluid}

Prolonged rupture of membranes is one of the conditions which is known to be associated with stimulation of cortisol production (Bauer et al, 1974) and acceleration of lung maturation (Richard- son et al, 1974). It is therefore assumed that rupture of the membranes acts in some way as a stressful situation for the fetus (Avery, 1975). Absence or gross deficiency of amniotic fluid is found in association with renal agenesis and some cases of renal cystic dysplasia. The common feature in all such cases is gross underdevelopment of the lower urinary tract indicating a lack of production of urine by the fetus (Perlman and Levin, 1974). These conditions are associated with the classical external features of Potter's syndrome and with marked pulmonary hypoplasia which normally causes death within a few hours of birth (Bain and Scott, 1960). Indeed there is good evidence that Potter's syndrome and pulmonary hypoplasia are due to lack of amniotic fluid, since they have been recorded in cases of prolonged rupture of membranes without renal malformation (Fantel and Shepard, 1975). Even more striking is the occasional case of renal agenesis without pulmonary hypoplasia or Potter's syndrome (Kohler, 1972; Mauer et al, 1974). These cases each involved one of a pair of monoamniotic twins. The fetus with renal agenesis thus floated in the amniotic fluid produced by its twin.

Loss of amniotic fluid is similar to maternal preeclampsia in that it may cause both reduced growth and increased maturity of the lungs, although the effects of oligohydramnios on the lung are very much more obvious than those of preeclampsia.

\section{Other Causes of Pulmonary Hypoplasia}

Other causes of pulmonary hypoplasia include congenital diaphragmatic hernia (usually absence of the left leaf of the diaphragm), abnormalities of the central nervous system such as anencephaly (Reale and Esterly, 1973), thanatophoric dwarfism, homozygous achondroplasia (Finegold et al, 1971), and, from personal experience, conditions such as severe $\mathbf{R h}$ isoimmunization associated with prolonged hydramnios and pleural effusions. Pulmonary hypoplasia has been recorded in cases of hydramnios where there was no other apparent abnormality (Bates, 1965). It would seem reasonable that any condition with gross distortion and reduction of the thoracic cavity might be associated with lung hypoplasia. The pathogenesis of pulmonary hypoplasia in abnormalities of the central nervous system and in cases with loss of amniotic fluid is less easy to understand, although some evidence as to the type of mechanism which may be involved is provided by animal experiments on the effects of decapitation and tracheal ligation. Decapitation in the rat fetus, which is usually followed by tracheal occlusion, causes increased lung size associated with retention of lung liquid (Blackburn et al, 1972, 1973). Measure- 
ment of the DNA content of the lungs indicated that there was an absolute increase in cell number. Earlier studies by Jost and Policard (1948) showed that decapitation of fetal rabbits by a technique which maintained tracheal patency resulted in thoracic narrowing and distortion with lung collapse. Maturation of the lung is retarded by the interruption of the pituitary-adrenal axis involved in such experiments, so that lung extracts at term do not lower surface tension in the normal way (Blackburn et al, 1972). Tracheal ligation in the fetal lamb, without interruption of the pituitary-adrenal axis, causes enormous increase in lung size up to 10 times normal weight at term associated with gross increase in lung liquid content (Lanman et al, 1971).

If accumulation of lung liquid is a stimulus to lung growth in utero both lack of amniotic fluid and increased external pressure might inhibit lung growth by preventing fluid retention within the airways. That lung growth can be severely impaired well after the embryonic period is demonstrated by the development of pulmonary hypoplasia following surgical production of a congenital diaphragmatic hernia in the fetal lamb at 120 days' gestation (deLorimier et $a l, 1967)$. If the operation was performed at less than 120 days' gestation there was failure of lung maturation as well.

Factors Concerned in Normal Lung Growth and Development and Possible Mechanisms for Growth Failure

It seems clear from the foregoing that airway pressure generated by alveolar liquid secretion is a stimulus to lung growth. It is not a very big step from this to consider whether perhaps fetal respiratory movements themselves might be important for normal lung development. Disuse atrophy or growth failure is a common phenomenon in muscular tissues and bones. In postnatal life prolonged collapse of one lung is unlikely to be seen during the growth period. It has, however, been suggested that bronchial obstruction, originating during an infection, may cause growth failure leading to McLeod's syndrome (Reid and Simon, 1962).

I would suggest that alveolar fluid production and fetal respiration in conjunction have a major role in ensuring normal development of the lung in utero, and that this function is taken over by air breathing after birth. The pituitary-adrenal axis modulates fetal lung growth mainly by influencing the timing of lung maturity. If this hypothesis is correct one might expect to see normal or excessive lung growth in fetuses with tracheal obstruction, even in the absence of respiratory activity, but failure of normal growth if the trachea were patent and breathing movements absent. Thus one could account for relatively normal development in lungs not connected to the trachea (Potter and Bohlander, 1941) and for the pulmonary hypoplasia seen in association with lesions of the central nervous system such as anencephaly. Failure of lung growth in association with prolonged lack of amniotic fluid may be due to inhibition of respiratory movements in this condition caused by the relatively cramped position of the fetus. One feature that is apparent on examining hypoplastic lungs is their relatively mature structure. Although hyaline membrane disease can occur in preterm babies with hypoplastic lungs it is fairly uncommon, and the respiratory distress of those delivered at term is due to the small lung size rather than to lack of surfactant.

\section{Prenatal Induction of Lung Maturity}

Acute loss of amniotic fluid resulting from ruptured membranes has been mentioned above as a cause of accelerated lung maturation by induction of a stress response with increased cortisol output. It is not immediately apparent, however, why loss of amniotic fluid should cause a stress response. Restriction of movement of a lamb fetus delivered into a saline bath is known to inhibit fetal breathing (Boddy and Dawes, 1975). If loss of amniotic fluid similarly inhibits fetal breathing in the human, could this be the stimulus for a stress reaction? Although the evidence for this is extremely tenuous it seems to me an attractive idea as it could explain a number of seemingly unrelated facts on the induction of lung maturity. It could well explain why such diverse factors as heroin administration (Taeusch et al, 1973), prolonged rupture of the membranes, and maternal preeclampsia, all induce lung maturation. Each of these is known to, or is likely to, cause fetal respiration to cease. Moreover, it would be of selective advantage for the fetus to react in this way since rupture of the membranes, or restriction of fetal movements by other means, is usually a sign that air breathing will shortly become necessary. The higher incidence of HMD following elective caeserean section would be due to lack of the stimulus to mature the surfactant pathways which is set in train by the onset of spontaneous labour. The increased incidence of HMD in the second, as compared to the first, of twins (Rokos et al, 1968) would result from lack of the advantage afforded to the first twin by inhibition of respiration through compression in the birth canal or rupture of membranes. In many ways this hypothesis is an inversion of older ideas, namely, that HMD results not from amniotic fluid inhalation but from failure to frighten 
the fetus into maturing his ${ }^{1}$ pathways for surfactant synthesis by stopping his breathing!

Although I recognize that the interactions I have proposed between fetal respiration, lung growth and surfactant synthesis may prove to be completely wrong these suggestions will have been worthwhile if they stimulate other workers to disprove them and to devise better ones.

'The word 'his' is used advisedly since this is predominantly a male problem.

\section{References}

Avery, M. E. (1975). Pharmacological approaches to the acceleration of fetal lung maturation. Brit. med. Bull., 31, 13-17.

Bain, A. D. and Scott, J. S. (1960). Renal agenesis and severe urinary tract dysplasia. Brit. Med. J., 1, 841-846.

Bates, H. R., Jr. (1965). Fetal pulmonary hypoplasia and hydramnios. Amer. J. Obstet. Gynec., 91, 295-296.

Bauer, C. R., Stern, L., and Colle, E. (1974). Prolonged rupture of membranes associated with a decreased incidence of respiratory distress syndrome. Pediatrics, 53, 7-12.

Blackburn, W. R., Kelly, J. S., Dickman, P. S., Travers, H., Lopata, M. A., and Rhoades, R. A. (1973). The role of the pituitary-adrenal-thyroid axis in lung differentiation II. Biochemical studies of developing lung in anencephalic fetal rats. Lab. Invest., 28, 352-360.

Blackburn, W. R., Travers, H., and Potter, D. M. (1972). The role of the pituitary-adrenal-thyroid axis in lung differentiation I. Studies of the cytology and physical properties of anencephalic fetal rat lung. Lab. Invest., 26, 306-318.

Boddy, K. and Dawes, G. S. (1975). Fetal breathing. Brit. med. Bull., 31, 3-7.

Boyden, E. A. (1974). The mode of origin of pulmonary acini and respiratory bronchioles in the fetal lung. Amer.J. Anat., 141, 317-328.

Brans, Y. W. and Cassady, G. (1975). Intrauterine growth and maturation in relation to fetal deprivation. In The Placenta and its Maternal Supply Line, edited by $\mathrm{P}$. Gruenwald, pp. 307-334. Medical and Technical Publishing Co., Lancaster.

Condorelli, S. and Scarpelli, E. M. (1975). Somatic-respiratory reflex and onset of regular breathing movements in the lamb fetus in utero. Pediat. Res., 9, 879-884.

Dawes, G. S., Fox, H. E., Leduc, B. M., Liggins, G. C., and Richards, R. T. (1972). Respiratory movements and rapid eye movement sleep in the foetal lamb. J. Physiol. (Lond.), 220, 119-143.

deLorimier, A. A., Tierney, D. F., and Parker, H. R. (1967). Hypoplastic lungs in fetal lambs with surgically produced congenital diaphragmatic hernia. Surgery, 62, 12-17.

Fantel, A. G. and Shepard, T. H. (1975). Potter syndrome: non-renal features induced by oligoamnios. Amer.J. Dis. Child., 129, 1346-1347.

Fedrick, J. and Butler, N. R. (1972). Hyaline-membrane disease. (Letter.) Lancet, 2, 768-769.

Finegold, M. J., Katzew, H., Genieser, N. B., and Becker,
M. H. (1971). Lung structure in thoracic dystrophy. Amer. J. Dis. Child., 122, 153-159.

Gluck, L. and Kulovich, M. V. (1973). Lecithin/sphingomyelin ratios in amniotic fluid in normal and abnormal pregnancy. Amer. J. Obstet. Gynec., 115, 539-546.

Gluck, L., Sribney, M., and Kulovich, M. V. (1967). The biochemical development of surface activity in mammalian lung. II. The biosynthesis of phospholipids in the lung of the developing rabbit fetus and newborn. Pediat. Res., 1, 247-265.

Hislop, A. and Reid, L. (1974). Development of the acinus in the human lung. Thorax, 29, 90-94.

Jost, A. and Policard, A. (1948). Contribution expérimentale à l'étude du développement prénatal du poumon chez le lapin. Arch. Anat. micr. Morph. exp., 37, 323-332.

Kohler, H. G. (1972). An unusual case of sirenomelia. Teratology, 6, 295-301.

Lanman, J. T., Schaffer, A., Herod, L. Ogawa, Y., and Castellanos, R. (1971). Distensibility of the fetal lung with fluid in sheep. Pediat. Res., 5, 586-590.

Mauer, S. M., Dobrin, R. S., and Vernier, R. L. (1974). Unilateral and bilateral renal agenesis in monoamniotic twins. J. Pediat., 84, 236-238.

Normand, I. C. S., Olver, R. E., Reynolds, E. O. R., and Strang, L. B. (1971). Permeability of lung capillaries and alveoli to non-electrolytes in the foetal lamb. J. Physiol. (Lond.), 219, 303-330.

Perlman, M. and Levin, M. (1974). Fetal pulmonary hypoplasia, anuria, and oligohydramnios: clinicopathologic observations and review of the literature. Amer. J. Obstet. Gynec., 118, 1119-1123.

Potter, E. L. and Bohlender, G. P. (1941). Intrauterine respiration in relation to development of the fetal lung. Amer. J. Obstet. Gynec., 42, 14-22.

Reale, F. R. and Esterly, J. R. (1973). Pulmonary hypoplasia: a morphometric study of the lungs of infants with diaphragmatic hernia, anencephaly, and renal malformations. Pediatrics, 51, 91-96.

Reid, L. and Simon, G. (1962). Unilateral lung transradiancy. Thorax, 17, 230-239.

Reynolds, E. O. R., Jacobson, H. N., Motoyama, E. K., Kikkawa, Y., Craig, J. M., Orzalesi, M. M., and Cook, C. D. (1965). The effect of immaturity and prenatal asphyxia on the lungs and pulmonary function of newborn lambs: the experimental production of respiratory distress. Pediatrics, 35, 382-392.

Reynolds, E. O. R., Roberton, N. R. C., and Wigglesworth, J. S. (1968). Hyaline membrane disease, respiratory distress, and surfactant deficiency. Pediatrics, 42, 758-768.

Richardson, C. J., Pomerance, J. J., Cunningham, M. D., and Gluck, L. (1974). Acceleration of fetal lung maturation following prolonged rupture of the membranes. Amer.J. Obstet. Gynec., 118, 1115-1118.

Rokos, J., Vaeusorn, O., Nachman, R., and Avery, M. E. (1968). Hyaline membrane disease in twins. Pediatrics, 42, 204-205.

Rudolph, A. J., Desmond. M. M., and Pineda, R. G. (1966). Clinical diagnosis of respiratory difficulty in the newborn. Pediat. Clin. N. Amer., 13, 669-692.

Snyder, F. F. (1961). Pulmonary hyaline membrane disease. Obstet. and Gynec., 18, 677-694.

Taeusch, H. W., Jr., Carson, S. H., Wang, N. S., and Avery, M. E. (1973). Heroin induction of lung maturation and growth retardation in fetal rabbits. J. Pediat., 82, 869-875. 